\title{
Melting, dehydration, and the dynamics of off-axis plume-ridge interaction
}

\author{
Paul S. Hall and Chris Kincaid \\ Graduate School of Oceanography, University of Rhode Island, Narragansett, Rhode Island 02882, USA \\ (phall@gso.uri.edu; kincaid@gso.uri.edu)
}

[1] We present results from a series of two-dimensional numerical experiments in which a thermally buoyant, off-axis mantle plume interacts with a nearby ridge axis. These experiments incorporate melting and a number of related dynamical feedbacks, including energy loss to latent heating and Fe depletion buoyancy as well as viscosity increases due to dehydration during melting. Results indicate that dehydration, which acts to increase the viscosity of the residual mantle during melting, profoundly impacts the morphology of flow between plume and ridge axis. As upwelling plume material begins to melt, it becomes significantly more viscous and readily accretes to the overlying lithosphere. This creates a viscous plug that grows downward from the base of the lithosphere directly above the plume conduit. Plume material traveling to the ridge axis is then deflected horizontally at subsolidus depths by this plug, allowing pristine, unmelted plume material to reach the ridge axis. Experiments without dehydration show that the loss of thermal energy to latent heating during melting marginally decreases the flow of plume material along the base of the lithosphere to the ridge axis. Alternatively, extraction of $\mathrm{Fe}$ from the solid during melting slightly increases plume flow to the ridge. These results also demonstrate that the flow of plume material to the ridge axis is sensitive to the slope of the base of the rheological lithosphere, consistent with previous studies of off-axis plume ridge interaction.

Components: 9993 words, 10 figures.

Keywords: plume; ridge; dehydration; melting.

Index Terms: 8121 Tectonophysics: Dynamics, convection currents and mantle plumes; 8150 Tectonophysics: Plate boundary_general (3040); 8162 Tectonophysics: Rheology—mantle.

Received 9 April 2003; Revised 20 July 2003; Accepted 21 July 2003; Published 16 September 2003.

Hall, P. S., and C. Kincaid, Melting, dehydration, and the dynamics of off-axis plume-ridge interaction, Geochem. Geophys. Geosyst., 4(9), 8510, doi:10.1029/2003GC000567, 2003.

Theme: Plume-Ridge Interaction Guest Editor: David Graham

\section{Introduction}

[2] Mantle plumes have been the focus of intense study since they were first proposed as the dynamical mechanism responsible for hot spots [Morgan, 1971]. Interest in potential interactions between mantle plumes and the large scale mantle convec- tion related to plate tectonics followed almost immediately after this initial proposal [e.g., Vogt, 1971; Schilling, 1973; Weinstein and Olson, 1989] and continues to this day. The most readily observed example of such interactions occurs when mantle plumes are located in the vicinity of the 
mid-ocean ridge system. Plume-ridge interaction is most clearly manifested where the plume is located directly beneath or immediately adjacent to the ridge axis, as occurs at, e.g., Iceland and the Azores. The geochemical and geophysical consequences of this relatively simple configuration are well documented. For example, the systematic variations in trace element concentrations (e.g., La/Sm) [Schilling, 1973], and isotope ratios (e.g., $\mathrm{Pb}, \mathrm{Sr}$ ) [Hart et al., 1973; Sun et al., 1975; Schilling et al., 1999] in basalts erupted along the Mid-Atlantic Ridge (MAR) near Iceland have been interpreted as resulting from the preferential flow of plume material along the ridge axis, away from Iceland. The existence of time transgressive V-shaped ridges along the Reykjanes ridge has similarly been attributed to the flow of plume material along the ridge axis [Vogt, 1971; Ito, 2001].

[3] The dynamics of on-axis plume-ridge interaction has been modeled extensively. Laboratory studies have considered the dispersion of compositionally buoyant on-axis plumes [Feighner and Richards, 1995], while numerical models have been used to investigate mantle flow associated with thermally buoyant on-axis plumes [Ribe et al., 1995]. More recently, numerical models of on-axis plume-ridge interaction have begun to consider the effects of melting on mantle flow through mechanisms such as latent heat loss, Fe-depletion buoyancy and melt retention buoyancy [Ito et al., 1996], viscosity increases related to dehydration [Ito et al., 1999], and temporal variations in the strength of plume flow [Ito, 2001].

[4] Off-axis plumes have been proposed to interact with nearby ridge axes via a pipeline-like flow along the base of the lithosphere [Morgan, 1978]. This hypothesis is supported by variations in offaxis gravity and bathymetry [Ito and Lin, 1995; Small, 1995] and along-axis variations in the geochemical properties of basalts (e.g., La/Sm [Douglass et al., 1995], Pb isotope ratios [Kingsley and Schilling, 1998; Douglass et al., 1999]) at ridge segments proximal to off-axis plumes. Consideration of the length of along-axis geochemical anomalies and excess crustal production at the associated ridge segments suggests that such a flow is possible for plume-ridge separation dis- tances of as much as $1700 \pm 250 \mathrm{~km}$ [Schilling, 1991]. Laboratory models of thermally buoyant off-axis plumes have suggested the viability of the pipeline model of plume-ridge flow [Kincaid et al., 1995] and numerical models using a thinlayer approximation have been used to develop scaling laws describing the spread of material from an off-axis thermal plume along the ridge axis [Ribe, 1996]. The importance of a strongly sloping rheological boundary layer (RBL) in facilitating flow to the ridge axis from the plume has been demonstrated using numerical models with compositionally buoyant plumes, which were also used to define flow regimes for the offaxis plume-ridge system [Kincaid et al., 1996]. However, attempts to investigate the dynamics of off-axis plume-ridge interaction have been limited in comparison to the on-axis case, and many questions remain regarding mantle flow in these systems.

[5] Previous attempts to study the dynamics of offaxis plume-ridge interaction have not included melting and its associated dynamical effects, nor have they considered the effect of dehydration. The effects of melting (e.g., latent heating, Fe depletion buoyancy) have been shown to be dynamically important at ridges [Cordery and Phipps Morgan, 1993; Su and Buck, 1993; Jha et al., 1994], for intraplate plumes [Manglik and Christensen, 1997; Leitch et al., 1998; Ribe and Christensen, 1999] and for on-axis plumes [Ito et al., 1996] and are therefore likely to be of importance in cases of offaxis plume-ridge interaction. Ito et al. [1997] included melting in their model of interaction between mantle plumes and migrating mid-ocean ridges, but did not emphasize the dynamical effects of melting. Laboratory experiments suggest that the presence of water may have a profound effect on the viscosity of peridotite, reducing the viscosity by 2 to 3 orders of magnitude relative to dry mantle at the same pressure and temperature [Hirth and Kohlstedt, 1996]. As a consequence, initially wet peridotite will experience a substantial increase in viscosity as it undergoes dehydration early in the melting process. This has been shown to affect mantle flow and melting at ridge axes [Braun et al., 2000; Hall and Parmentier, 2000]. The issue of 
water content is particularly important in studies of plumes, which can have water contents significantly greater than ambient upper mantle material [Schilling et al., 1983; Wallace, 1998], and dehydration has been shown to significantly alter flow beneath the ridge in on-axis plume-ridge systems [Ito et al., 1999].

[6] We present results from a series of two-dimensional (2-D) numerical experiments in which a thermally buoyant plume interacts with a nearby ridge. The model improves upon previous efforts by incorporating melting and a number of related dynamical feedbacks, including latent heating and Fe depletion buoyancy. In addition, viscosity increases due to dehydration during melting are considered. Our experiments indicate that the flow of plume material to the ridge axis is sensitive to the slope of the base of the rheological lithosphere, with communication between the plume and the ridge enhanced as this slope increases. This agrees with the results of previous experiments that investigated chemically buoyant plumes [Kincaid et al., 1996]. Furthermore, the loss of thermal energy to latent heating during melting marginally decreases the flow of plume material to nearby ridge axes while extraction of $\mathrm{Fe}$ from the solid slightly increases plume flow to the ridge. Dehydration related increases in the viscosity of the residual mantle during melting are found to significantly alter the morphology of flow between plume and ridge axis. As ascending plume material begins to melt off-axis, a viscous plug forms at the base of the lithosphere over the plume conduit. This plug causes the upwelling plume material to spread horizontally at subsolidus depths and consequently less plume material arrives at the ridge axis. The viscous boundary created by this plug is effectively equivalent to a thickened lithosphere with a nearly horizontal base. Because of this, flow to the ridge axis is independent of the slope of the base of the lithosphere when dehydration is considered. Finally, because the plume material traveling to the ridge axis under these circumstances spreads horizontally under subsolidus conditions, plume material that does reach the ridge axis has experienced little or no melting prior to reaching the ridge axis. This implies a significantly different source chemistry at the ridge axis than would be expected without dehydration.

\section{Model}

\subsection{Conceptual Model}

[7] Plume-ridge interaction may be described by the plume-source/ridge-sink model (Figure 1a). A nearridge plume moves vertically through the mantle due to buoyancy forces until it impinges on the sloping base of the lithosphere, where the plume begins to spread horizontally along the base of the lithosphere. The subsequent horizontal dispersion of the plume is governed by the balance between the viscous drag imparted by the motion of the overlying plate and the ambient mantle and gravitational spreading of the buoyant plume material, which drives the plume material upslope along the base of the lithosphere (i.e., toward the nearby ridge) [Ribe, 1996]. This force balance is controlled in part by the difference between plume and ambient mantle viscosities [Griffiths and Campbell, 1991]. Observations suggest that plumes can interact with ridges located at distances in excess of $1000 \mathrm{~km}$ from the plume [Schilling, 1991]. Interaction at such great distances is likely facilitated by thermal erosion of the cold overlying lithosphere by hot plume material [Olson et al., 1988; Kincaid et al., 1995, 1996]. This could enhance ridgeward flow of plume material by carving a subhorizontal channel through the base of the lithosphere within which plume flow could be focused [Schilling, 1985]. Three-dimensional laboratory models support the notion of a relatively narrow subhorizontal channel supplying plume material to the ridge [Kincaid et al., 1995]. Conversely, thermal erosion may actually inhibit plume-ridge interaction by creating a pocket in the lithosphere off-axis, trapping ascending plume material, which is subsequently dragged away by the plate [Kincaid et al., 1996].

\subsection{Numerical Model}

[8] Numerical experiments are conducted which model mantle flow in the plume-ridge system as convection of a viscous, Boussinesq, Newtonian fluid within a two-dimensional (2-D), regular Cartesian domain (Figure 1b). The relevant system of 
a)
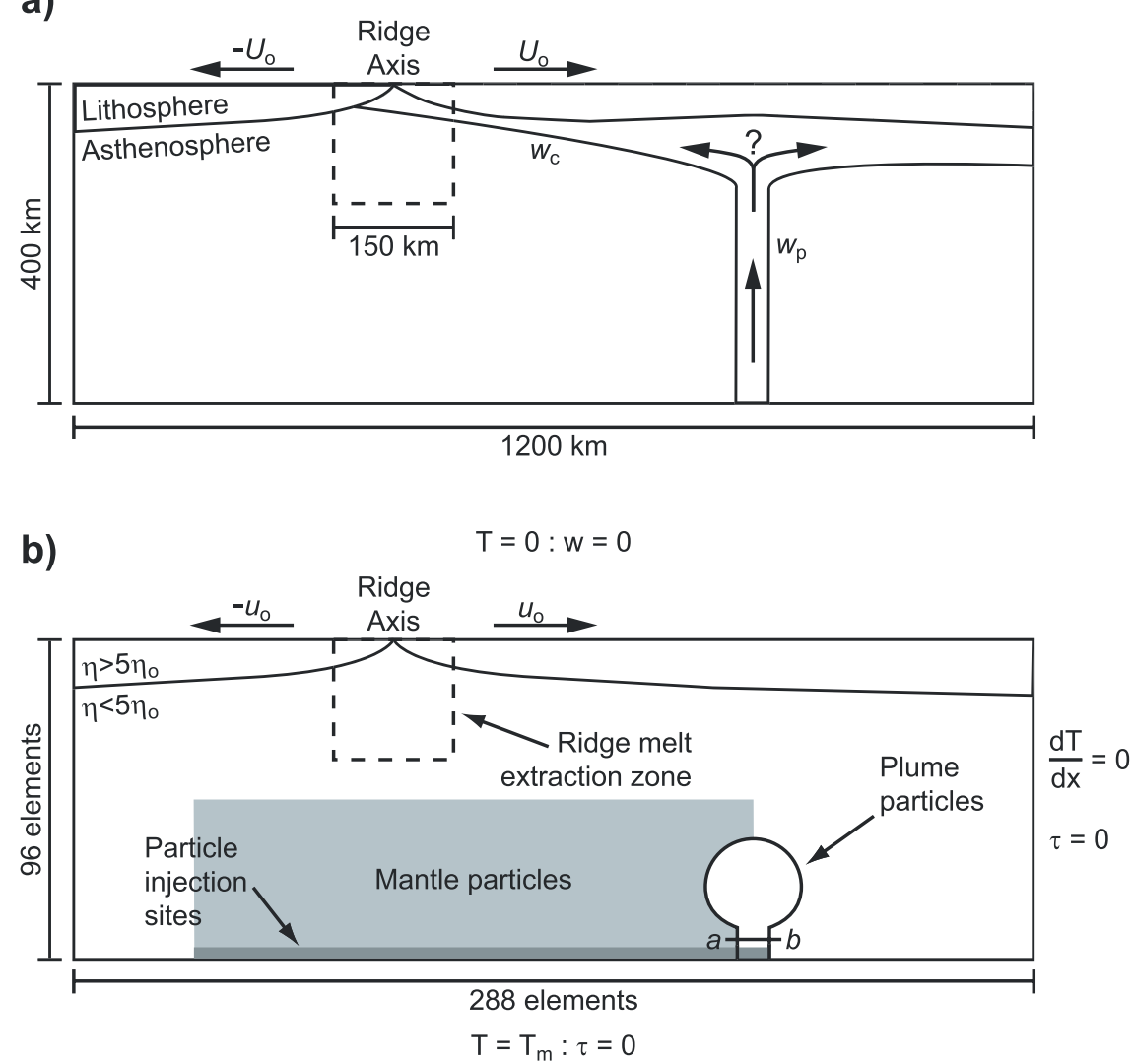

Figure 1. a) Cartoon illustration of the plume-source/ridge-sink model. A near-ridge plume rises through the upper mantle and then flows along the sloping base of the overlying lithosphere toward the ridge. $U_{0}$ is the velocity of the plate and $w_{\mathrm{p}}$ and $w_{\mathrm{c}}$ are the maximum velocities of material in the plume conduit and the subhorizontal plume channel, respectively. b) A cartoon illustration of the numerical model. The initial distribution of mantle and plume particles is shown. Additional particles are introduced at particle injection sites along the bottom boundary as needed. Plume concentration at the ridge axis is computed at every timestep as the percentage of particles within the ridge melt extraction zone identified as plume particles. Likewise, the flux of plume material to the ridge axis is computed as the ratio of the number of plume particles entering the ridge melt extraction zone at a given timestep to the number of plume particles crossing the line $a-b$ during that timestep.

dimensionless model equations to be solved includes the conservation of mass (1), momentum (2) and energy (3), which can be expressed in vector notation as

$$
\begin{gathered}
\nabla \cdot \boldsymbol{u}=0 \\
\nabla \cdot \boldsymbol{\tau}+\nabla p=\operatorname{Ra} T \hat{\mathrm{k}}+\mathrm{BRa} D \hat{\mathrm{k}} \\
\frac{\partial T}{\partial t}=-\boldsymbol{u} \cdot \nabla T+\nabla^{2} T-\Phi_{\mathrm{L}}
\end{gathered}
$$

Dimensionless variables $\boldsymbol{u}, \boldsymbol{\tau}, p, T$ and $D$ are the velocity vector, the viscous stress tensor, pressure, potential temperature and melt depletion, respectively, and $\hat{\mathrm{k}}$ is the unit vector in the vertical direction. $\Phi_{\mathrm{L}}$ represents heat loss due to latent heating during melting and is described below. Buoyancy forces acting on the fluid are accounted for in the body force term of the momentum equation (2) through a combination of the thermal Rayleigh number,

$$
\mathrm{Ra}=\frac{\mathrm{g} \alpha \Delta \mathrm{Td}^{3}}{\kappa \eta_{0}}
$$

and a dimensionless buoyancy parameter,

$$
\mathrm{B}=\frac{\beta}{\alpha \Delta \mathrm{T}}
$$

which accounts for buoyancy due to the extraction of $\mathrm{Fe}$ from the residue during melting. Here 
$\Delta \mathrm{T}$ is the total dimensional potential temperature contrast between the top and bottom of the model domain $\left(1350^{\circ} \mathrm{C}\right)$, and $\beta$ is the chemical buoyancy coefficient $(0.06$, appropriate for melting in the presence of residual garnet [Sparks and Parmentier, 1993; Manglik and Christensen, 1997]). Thus the extraction of $25 \%$ melt yields a buoyancy force on the residue equivalent to an increase in temperature of $430^{\circ} \mathrm{C}$. The parameters $\mathrm{g}, \alpha, \mathrm{d}, \kappa, \eta_{0}$ and $\rho_{0}$ are gravitational acceleration, thermal expansivity, fluid thickness, thermal diffusivity, reference mantle kinematic viscosity and reference mantle density.

[9] A non-diffusive Lagrangian particle technique is employed for tracking fluid chemistries and implementing melting [Kincaid et al., 1996; Manglik and Christensen, 1997; Kincaid and Hall, 2003]. Individual particles are transported through the model domain by solving the advection equation,

$$
\frac{\mathrm{d} \boldsymbol{x}}{\mathrm{d} t}=\boldsymbol{u}
$$

for each particle using a Runge-Kutta step. Here $\boldsymbol{x}$ is the position vector for the particle. Melting is modeled on the scale of the individual particles. For a given particle, the energy available for melting is related to the difference between the temperature of the particle and the temperature of the solidus for that particle at the same depth. In order to determine the incremental degree of melting (or depletion), $\Delta D$, this energy is partitioned between heat loss to latent heating and isobaric melt production [Langmuir et al., 1992]:

$$
\Delta D=\frac{T_{R}-T_{S}}{\left.\frac{\mathrm{d} T}{\mathrm{~d} D}\right|_{\mathrm{p}}+\frac{T_{R} \Delta S}{\mathrm{C}_{\mathrm{p}}}}
$$

where $T_{R}$ is the particle temperature, including the mantle adiabatic gradient $\left(\mathrm{d} T / \mathrm{d} z=0.5^{\circ} \mathrm{C} \mathrm{km}^{-1}\right)$. $T_{S}$ is the solidus temperature, $\Delta \mathrm{S}$ is the entropy of fusion for peridotite, $\mathrm{C}_{\mathrm{p}}$ is the heat capacity of peridotite, and $\left.(\mathrm{d} T / \mathrm{d} D)\right|_{\mathrm{p}}$ is one over the isobaric melt productivity, which is related to the temperature difference between contours of constant depletion at a given depth. Once the incremental degree of melting is determined, the temperature change due to latent heating is calculated,

$$
\Delta T_{R}=\frac{T_{R} \Delta \mathrm{S}}{\mathrm{C}_{\mathrm{p}}} \Delta D
$$

and the temperature of the particle is adjusted accordingly (Figure 2). This is accomplished by applying the temperature correction, weighted by the local particle density, to the grid nodes of the computational element in which the particle is located. The total amount of melting (or depletion) experienced by each particle throughout its history is tracked. We use a parameterization of the peridotite solidus and liquidus [McKenzie and Bickle, 1988], and assume the contours of constant depletion to be spaced uniformly between the solidus and liquidus at any given depth. Melting is only calculated relative to the dry solidus. Thus we ignore the small amount of melt produced between the wet and dry solidi ( $\sim 1 \%$ [Hirth and Kohlstedt, 1996]). We adopt a value of $400 \mathrm{~J} \mathrm{~kg}^{-1}{ }^{\circ} \mathrm{C}^{-1}$ for the entropy of fusion and a heat capacity of $1250 \mathrm{~J} \mathrm{~kg}^{-1}{ }^{\circ} \mathrm{C}^{-1}$ [Manglik and Christensen, 1997]. Melt is extracted from the individual particles at every time step in what amounts to an incremental fractional melting model. Melt depletion at the level of the grid is then determined at the grid nodes by averaging the depletion of the particles in the adjoining computational elements.

[10] Viscosity is modeled using an Arrhenius law relationship modified by several pre-exponential coefficients [Kincaid et al., 1996],

$$
\eta=A_{1} A_{2} \eta_{0}\left\{\max \left(1, \exp \left[\mathrm{E}\left(\frac{1}{T}-1\right)\right]\right)\right\}
$$

where $\mathrm{E}$ is a dimensionless parameter related directly to the activation energy, $\varepsilon$, and inversely to the total dimensional potential temperature contrast across the model, $\Delta \mathrm{T}$, and the ideal gas constant, R (i.e., $\mathrm{E}=\varepsilon / \mathrm{R} \Delta \mathrm{T}$ ). The exponential term creates a highly viscous plate along the cold upper boundary of the model domain. For a given temperature profile, the thickness of this rheological boundary layer (RBL) is controlled by $\mathrm{E}$ (Figures $3 \mathrm{a}$ and $3 \mathrm{~b}$ ). The "max" function, which 


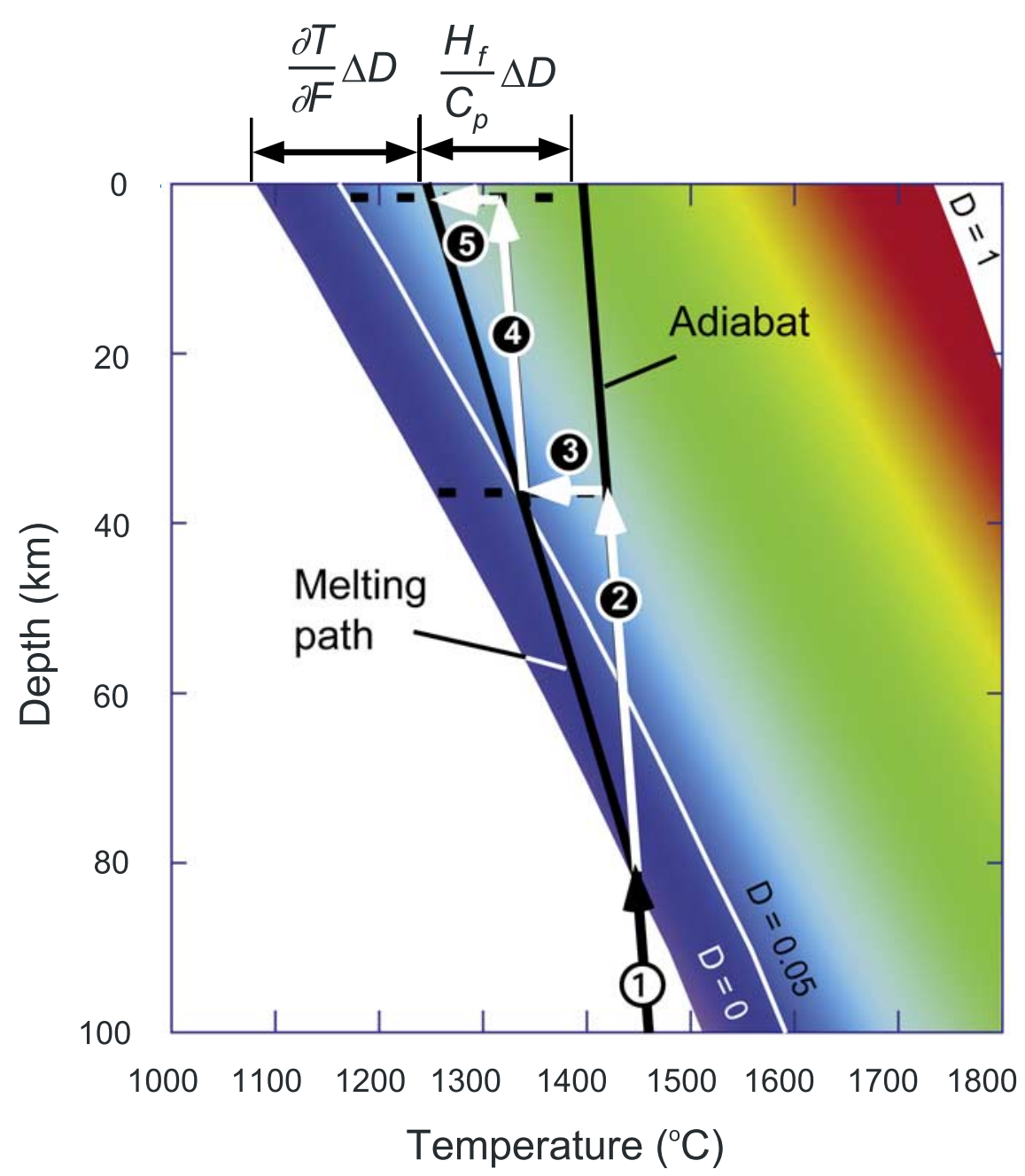

Figure 2. Cartoon illustration of melting as implemented in the model. 1) A mantle particle ascending adiabatically approaches the solidus. 2) The particle crosses the solidus following an adiabatic path. 3) At the end of the advective step, the amount of melting undergone by the particle is computed by comparing its temperature to that of the solidus, balancing the available thermal energy between latent heating and elevating the temperature of the remaining solid (see equation (7)). The temperature of the particle is then corrected for latent heating. 4) The particle continues its ascent adiabatically. 5) At the end of the advective step, the amount of melting undergone by the particle is computed as in step 3, with the particle temperature being compared to that of the adjusted solidus (i.e., taking into account previous melting) to determine the available thermal energy. The temperature of the particle is then corrected for latent heating, as in step 3. Steps 4 and 5 are repeated with each advective step until the particle leaves the model domain.

returns the maximum of either the exponential term or one, allows viscosity decreases due to high temperatures associated with the plume $(\mathrm{T}>1)$ to be isolated in the pre-exponential terms and controlled explicitly. The pre-exponential coefficient $A_{1}$ is used to model viscosity reduction due to the temperature anomaly associated with the plume. This additional temperature dependence of the viscosity law is handled explicitly so that a variety of plume viscosities could be investigated without altering the structure of the RBL. This relationship is given by

$$
A_{1}=\frac{1}{1+\left[\left(\frac{\Delta \eta_{\mathrm{T}}-1}{2}\right)\left(1+\tanh \left(\gamma\left(T-\mathrm{T}_{\mathrm{p}}\right)\right)\right)\right]}
$$

where $\gamma$ is a parameter controlling the sharpness of the decrease in viscosity, $\Delta \eta_{\mathrm{T}}$ controls the magnitude of the viscosity reduction, and $T_{p}$ is the dimensionless plume temperature [Kincaid et 
al., 1996]. For example, a value of 10 for $\Delta \eta_{\mathrm{T}}$ (the maximum used in this study) results in a minimum value of 0.1 for $A_{1}$ when $T=\mathrm{T}_{\mathrm{p}}$, and therefore a maximum of a factor of 10 reduction of viscosity in (9). In the experiments presented here plumes are assumed to have a potential temperature $200^{\circ} \mathrm{C}$ above that of ambient mantle, while the ambient mantle temperature is taken to be $1350^{\circ} \mathrm{C}$, giving $\mathrm{T}_{\mathrm{p}}=1.038$. We simulate the effect of dehydration on viscosity with the second pre-exponential coefficient, $A_{2}$. We assume an abrupt increase in
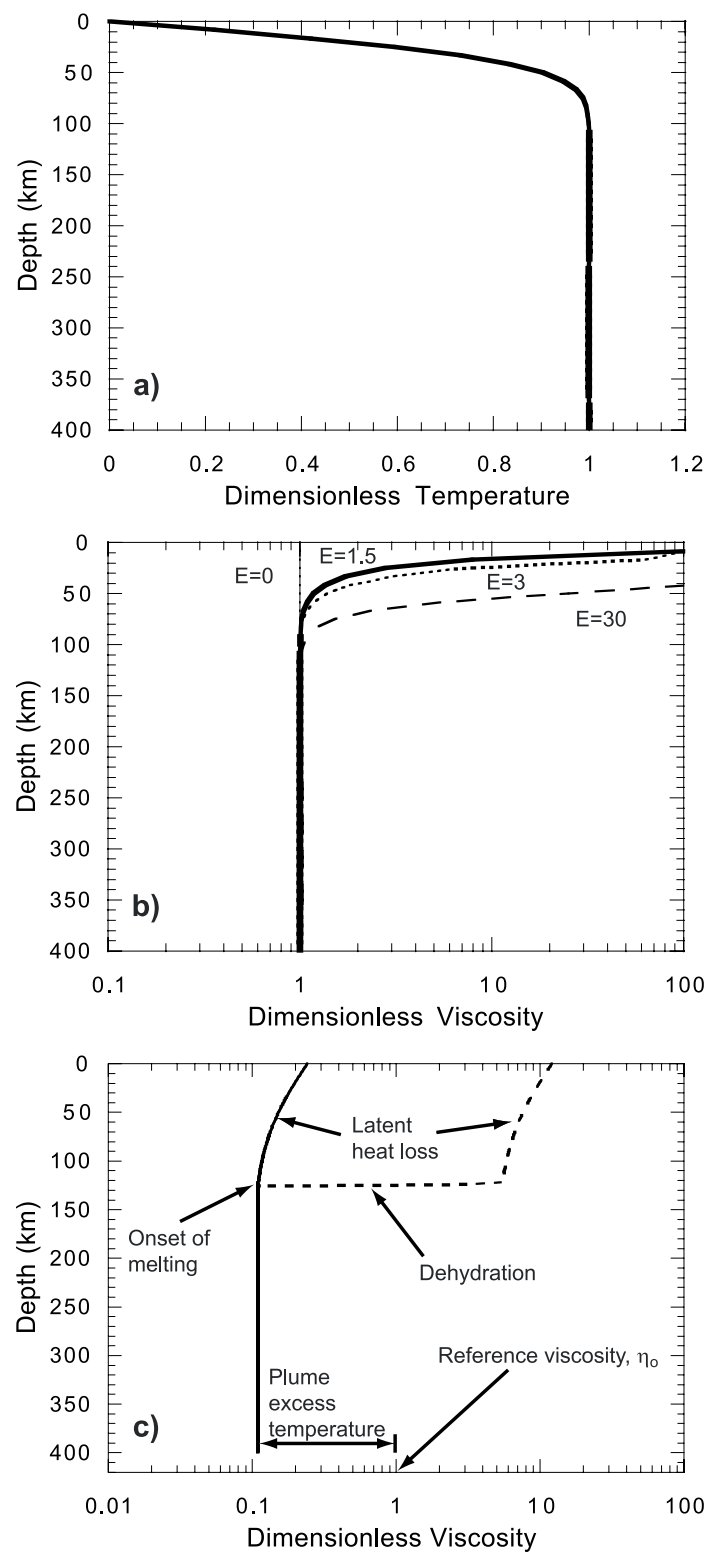

Figure 3 viscosity by a factor of 50 during the first 1\% melting at the dry solidus, so that $A_{2}$ has a value of 1 for $D=0$ and a value of 50 for $D \geq 0.01$ (Figure 2c) [Ito et al., 1999]. $A_{2}$ increases linearly between $D=0$ and $D=0.01$. A maximum cut-off viscosity of $\eta_{\max }=100 \eta_{0}$ is used, and the minimum model viscosity, found in the hot plume, is $\eta_{\min }=0.1 \eta_{0}$. This gives a maximum viscosity variation of $10^{3}$ within the model.

[11] These numerical experiments are conducted in a 2-D model domain representing a vertical slice through the upper mantle oriented perpendicular to the ridge axis and passing through the center of the plume (Figure 1b). The model domain has an aspect ratio of $3: 1$, corresponding to horizontal and vertical dimensions of $1200 \mathrm{~km}$ and $400 \mathrm{~km}$, respectively. The computational grid is regular and Cartesian, with 288 elements in the horizontal and 96 in the vertical. The top boundary is impermeable and has a fixed temperature $(T=0)$. The bottom boundary is permeable and stress-free with a fixed temperature $\left(T=\mathrm{T}_{\mathrm{m}}\right)$. Sidewalls are permeable, stress-free and insulating. Material is free to enter or leave the domain through the bottom or either of the side boundaries.

[12] Spreading plates are represented by a divergent horizontal velocity imposed along the upper boundary. A horizontal velocity $\pm U_{0}$, corresponding to the plate velocity, is assigned along the top boundary.

Figure 3. (opposite) Profiles of $T$ (a) and $\eta$ (b) versus depth in the model domain, demonstrating the relative thermal and rheological boundary layers for various values of the dimensionless activation energy, $E$. For a given temperature profile, larger values of $E$ lead to a thicker, more strongly sloping rheological boundary layer. c) The effect of latent heat loss and melting on viscosity. The profile follows a single plume particle from the base of the model domain to the surface, with and without consideration of dehydration effects. Viscosity is initially diminished relative to the reference mantle viscosity because of the higher plume temperature. As the particle ascends, it begins to melt at a depth of $\sim 125 \mathrm{~km}$. If dehydration is considered (dashed path), the viscosity of the particle increases by a factor of 50 over the first $1 \%$ of melting. Further upwelling brings additional melting and a decrease in particle temperature due to loss of heat to latent heating. This decrease in temperature leads to increases in viscosity. 
This prescribed plate speed is zero at the ridge axis and increases linearly to a constant value within three grid points on either side of the ridge axis. The velocities on each side of the ridge axis are equal in magnitude, but opposite in sign, so as to induce a symmetric corner flow. Plate scale flow within the model domain is therefore assumed to be a passive response to the motion of plates which are driven by body forces concentrated far outside the model boundaries.

[13] In order to best utilize the model to investigate flow between the plume and the ridge axis, the ridge and plume are both positioned off-center within the model domain. The ridge is located to the left of center, while the plume is located to the right. While previous studies have demonstrated that the flux of plume material from an off-axis plume to a ridge decreases with increasing plumeridge separation [Kincaid et al., 1996], the distance between the plume and the ridge is held constant in these experiments $\left(L_{\mathrm{pr}}=450 \mathrm{~km}\right)$.

[14] Separate clouds of Lagrangian particles, designated "plume mantle" and "ambient mantle" particles, are initially distributed within the model domain as in Figure 1b. Additional particles are added to the domain along the bottom boundary as particles are advected away with the flow so as to maintain a constant density of particles. Particles leaving the model domain through the bottom or either of the side boundaries are no longer tracked. Thermal buoyancy is imparted to the plume particles by assigning temperatures that are elevated relative to the ambient mantle rising through the bottom boundary to the nodes in the plume source region. We assume a plume temperature anomaly, or excess temperature, of $200^{\circ} \mathrm{C}$ in this region.

[15] The system of model equations are solved subject to the stated boundary and initial conditions using a penalty function, finite element technique which utilizes bilinear splines [Hughes, 1987]. These methods have been employed previously for studies of mantle convection in plume-ridge systems [Kincaid et al., 1996] as well as at subduction zones [Kincaid and Sacks, 1997; Kincaid and Hall, 2003], and have been thoroughly benchmarked [Travis et al., 1991]. Experiments are first run without plumes to produce a steady state thermal structure characteristic of spreading ridges, in which the cold RBL thickens with distance away from the ridge axis as a function of spreading rate. The temperature and viscosity fields from these runs serve as initial conditions for the plume-ridge experiments.

\section{Results}

[16] As an ascending plume impinges on the base of the overlying lithosphere, buoyancy forces drive the plume material upward along the sloping base of the overlying lithosphere toward the ridge axis. At the same time, viscous forces associated with the motion of the overlying plate oppose this ridgeward flow, dragging plume material away from the ridge axis. The strength of the subhorizontal plume flow can be characterized by a theoretical plume channel Peclet number, defined as [Kincaid et al., 1996]

$$
P e_{p}=\frac{w_{c} d}{\kappa}
$$

where $\kappa$ is the thermal diffusivity of the mantle, $d$ is the fluid layer thickness and $w_{c}$ is the velocity of plume material as it travels horizontally along the base of the lithosphere. This last quantity is a function of the slope of the lithosphere, which is itself related to the dimensionless activation energy $\mathrm{E}$, and the viscosity of the plume material, $\eta$ [Kincaid et al., 1996]. Likewise, the strength of the plate flow can be quantified by the plate Peclet number:

$$
P e=\frac{U_{o} d}{\kappa}
$$

Mantle flow in plume-ridge systems is governed by the balance between these two competing forces. This balance can be characterized by the ratio $\left(P^{*}\right)$ of the plume Peclet number to the plate Peclet number [Kincaid et al., 1996]:

$$
P^{*}=\frac{P e_{p}}{P e}
$$

Thus $P^{*}$ is essentially the ratio of the plume velocity along the base of the lithosphere, $w_{c}$, to the plate velocity, $U_{0}$, and large values of $P^{*}$ 
correspond to relatively strong plume flow and weak plate flow while small values of $P^{*}$ indicate weak plume flow and strong plate flow. This single parameter, which encapsulates much of the dynamics of the plume-ridge system, can be systematically varied to explore the full range of plume-ridge interaction. In these experiments we vary three parameters $(\eta, \mathrm{E}$ and $P e)$ independently to obtain a wide range of values for $P^{*}$. Specifically, we control the strength of plume flow through the ratio of plume to ambient mantle viscosity, $\eta / \eta_{0}$, and the dimensionless activation energy, E, which controls the slope of the base of the lithosphere. These parameters are used to calculate a theoretical plume velocity, $w_{c}$, which is then used to determine $P^{*}$ [Kincaid et al., 1996]. Plume viscosity contrast, which is controlled by varying $\Delta \eta_{\mathrm{T}}$ in $(10)$, covers a range of $0.1 \leq \eta / \eta_{0} \leq 1$ in these experiments, while dimensionless activation energy varies over $0 \leq \mathrm{E} \leq 30$. The strength of plate flow is controlled with the plate Peclet number, $P e$. Plate Peclet numbers considered here range over $100 \leq P e \leq 1100$ (corresponding to plate velocities of $0.8 \mathrm{~cm} \mathrm{yr}^{-1} \leq U_{0} \leq 8.8 \mathrm{~cm} \mathrm{yr}^{-1}$ ). These control parameters combine to give values of $P^{*}$ ranging from $0.5 \leq P^{*} \leq 2.8$. The full variety of plume-ridge interaction behavior, from strong to no communication, is observed in this range.

[17] A number of measures can be used to quantify the character of communication between plume and ridge. The most straightforward methods involve characterizing the plume material reaching the ridge axis. To this end we define a square region centered immediately beneath the ridge axis, with sides that scale to $150 \mathrm{~km}$ in length, as the ridge melt extraction zone (Figure 1a). This area defines roughly the region in which melt derived from plume particles might potentially appear at the ridge axis. The first measure of plume-ridge communication corresponds to the proportion of the plume flux entering the ridge melt extraction zone, $Q^{*}$. Computationally this is determined by taking the ratio of the number of plume particles entering the ridge melt extraction zone to the number of plume particles entering the model domain across the base of the plume conduit at a given instant. Conceptually, in the absence of a sloping base of the lithosphere and plate motion, a symmetrically spreading off-axis plume would yield a value of $Q^{*}=0.5$, i.e., $50 \%$ of the plume would reach the ridge axis (in a 2-D world). Building on this, if the base of the lithosphere is sloped toward the ridge axis one would expect $Q^{*} \geqslant 0.5$ in the absence of plate flow, as buoyant plume material would run preferentially uphill toward the ridge axis (analogous to water running down a slope to a drain). Conversely, the movement of plates away from the ridge axis in the absence of a sloping base to the lithosphere would lead to $Q^{*} \leq 0.5$ as plume material is preferentially pulled away from the ridge axis by the shear flow imposed by the plate motion.

[18] A second measure of plume-ridge communication is the proportion of material beneath the ridge axis that derives from the plume, $X^{*}$. This is simply calculated as the ratio of the number of plume particles within the ridge melt extraction zone to the total number of particles (i.e., plume plus ambient mantle particles) in the extraction zone at a given instant. This is then related to the character of the source of any melt extracted at the ridge axis. Melt migration processes will add complexity to this relationship, but plume-ridge interaction scenarios with large values of $X^{*}$ would be expected to lead to melts at the ridge axis with stronger plume geochemical signatures than scenarios with small values of $X^{*}$.

[19] A measure of plume-ridge communication which more explicitly considers the geochemical consequences of the associated mantle flow is the degree to which plume material reaching the ridge extraction zone has undergone prior episodes of melting and melt extraction. This can be quantified by considering the average degree of depletion already experienced by all plume particle entering the ridge melt extraction zone at a given instant, $D^{*}$. Plume material which has undergone melt extraction prior to reaching the ridge axis will be depleted in incompatible elements and will therefore contribute less to the geochemical character of ridge melts than more pristine plume material would. The smaller the value of $D^{*}$ the more pristine the plume material at the ridge axis and 

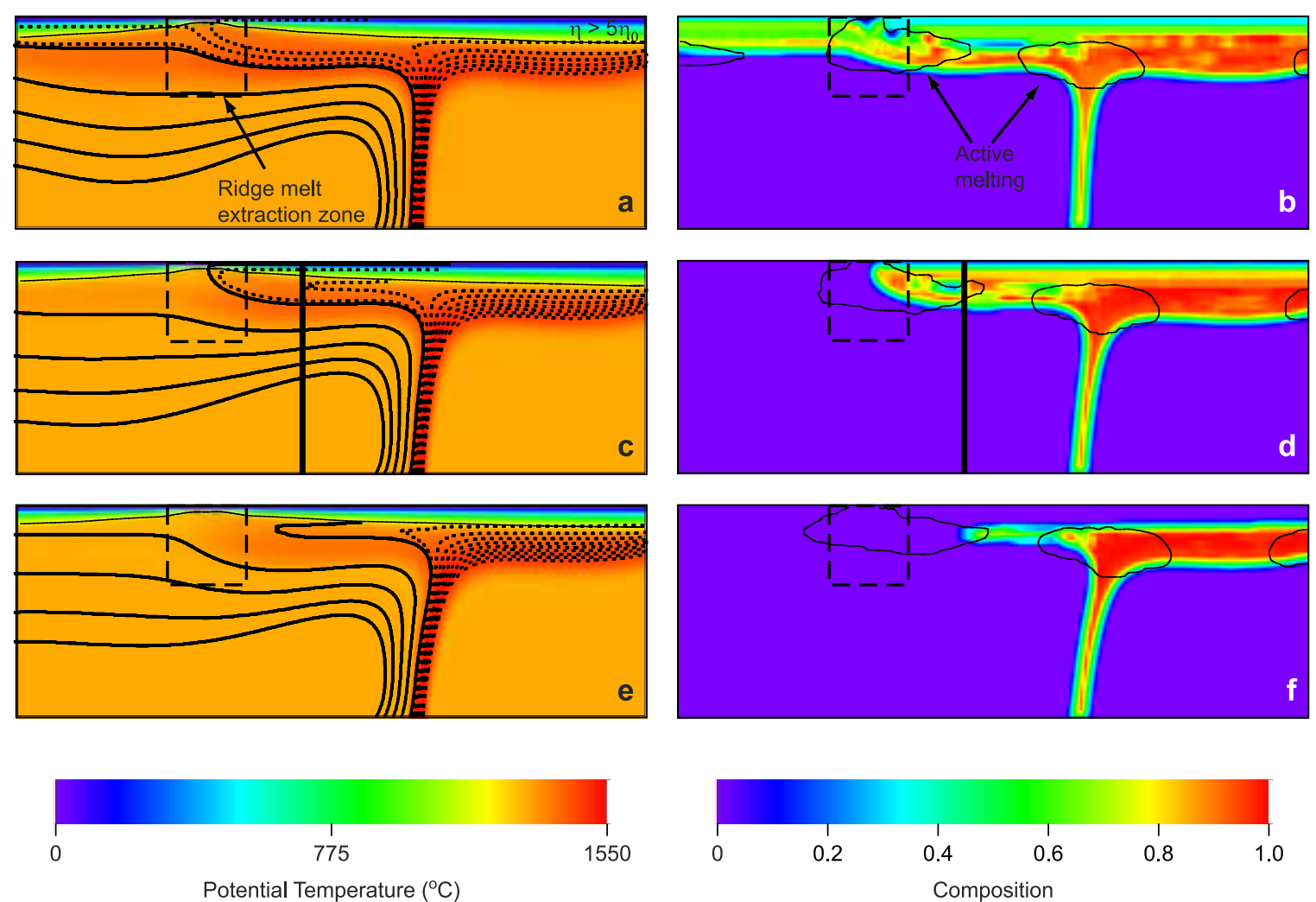

Figure 4. Temperature (left) and composition (right) fields for three model runs in which only the latent heat effects of melting are accounted for: $\mathrm{a}, \mathrm{b}) P^{*}=0.9\left(\mathrm{E}=30, \eta / \eta_{0}=0.1, \mathrm{Pe}=600\right)$; c, d) $P^{*}=0.6\left(\mathrm{E}=30, \eta / \eta_{0}=0.1, \mathrm{Pe}=\right.$ 900); e, f) $P^{*}=0.5\left(\mathrm{E}=30, \eta / \eta_{0}=0.1, P e=1100\right)$. The path lines of selected mantle (solid) and plume (dotted) particles are superimposed on the temperature field. The base of the rheological lithosphere, defined by the $\eta=5 \eta_{\mathrm{o}}$ isoviscous contour is overlain in a, $\mathrm{c}$ and e. Regions of active melt generation are outlined in $\mathrm{b}$, $\mathrm{d}$ and $\mathrm{f}$. The bold vertical line in $\mathrm{c}$ and $\mathrm{d}$ marks the location of the vertical profile shown in Figure 8. Composition is obtained by normalizing the number of plume particles in a given computational cell by the maximum initial number of particles per cell.

the stronger the plume signature in the chemistry of any ridge melts.

\subsection{First-Order Effects of Melting: Latent Heat}

[20] Experiments were conducted which consider melting and the associated loss of thermal energy to latent heating effects. These experiments begin with the plume and ambient mantle particles distributed as shown in Figure 1b. The first plume particles to reach the ridge typically arrive at the ridge melt extraction zone within 2 Myr of the start of the experiment. This is followed by a large pulse of plume material to the ridge axis, related to the plume head. This initial pulse dies away by approximately $10 \mathrm{Myr}$ from the start of the experiment. A period of unsteady flow follows, lasting
20-30 Myr, during which the flux of plume material to the ridge axis can fluctuate considerably. The magnitude of these fluctuations decrease throughout this period, and an essentially steady state is achieved by 40 Myr from the start of the experiments. Experiments are typically run to in excess of 55 Myr.

[21] Plume-ridge communication ranged from noninteraction for values of $P^{*}<0.5$ to robust interaction for $P^{*}>1$.9. Differences in flow morphology across this range of communication scenarios can be discerned by considering the temperature and composition fields and particle path lines for experiments with different values of $P^{*}$ (Figure 4). For cases with robust interaction (Figures $4 \mathrm{a}$ and $4 \mathrm{~b}$ ), a significant fraction of plume material enters the ridge extraction box. Much of this material then 


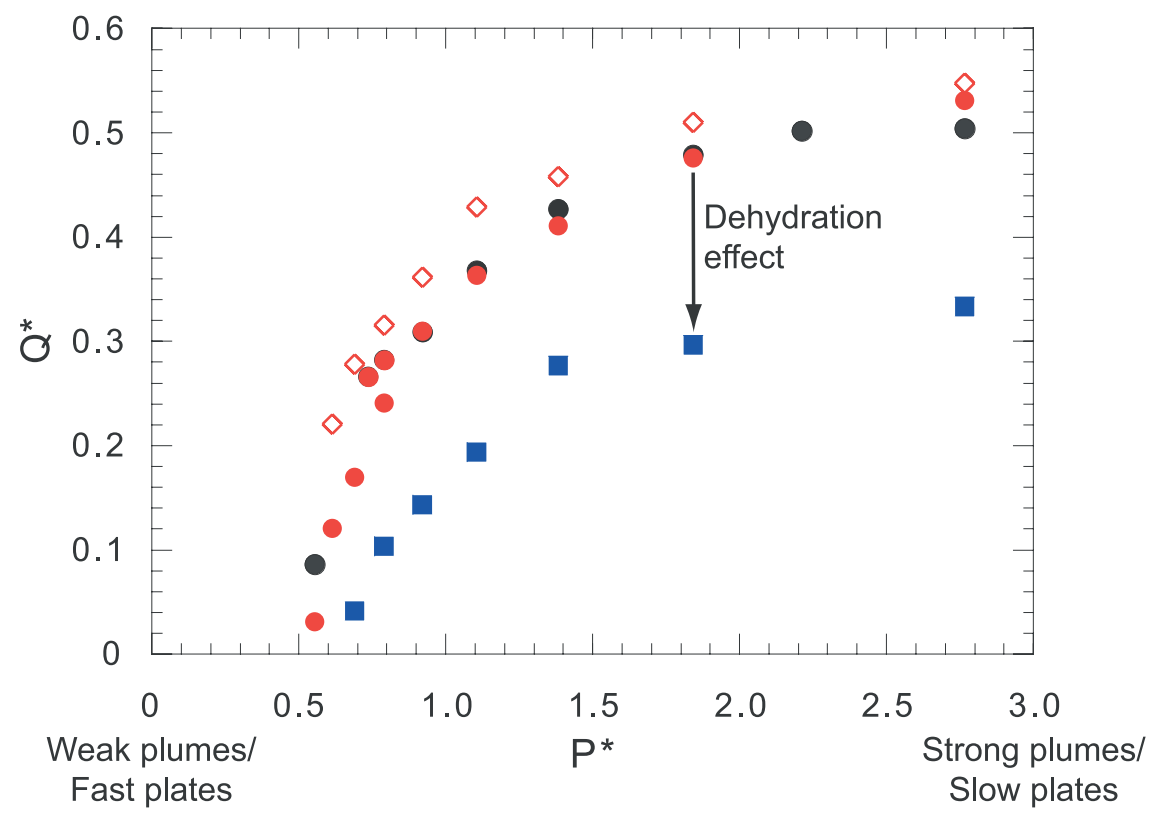

Figure 5. Fractional plume flow toward the ridge axis $\left(Q^{*}\right)$ as a function of the ratio of plume Peclet number to plate Peclet number $\left(P^{*}\right)$ for cases with no melting (black circle); melting and latent heat effects (red circle); melting, latent heating and Fe depletion buoyancy (red diamond); and melting, latent heating and dehydration (blue square). Stronger plumes and/or slower plates, and hence higher values of $P^{*}$, lead to more plume material being channeled toward the ridge axis. While latent heating and Fe depletion buoyancy produce marginal effects, viscosity increases related to dehydration during melting significantly reduce the flow of the plume toward the ridge axis.

crosses the ridge axis and accretes to the lithosphere on the far side of the ridge. For cases with more moderate interaction (Figures $4 \mathrm{c}$ and $4 \mathrm{~d}$ ), a smaller fraction of plume material enters the ridge extraction box (e.g., 1 plume particle trajectory in Figure $4 \mathrm{c}$ as opposed to 3 in Figure 4a). In addition, plume material only accretes to the lithosphere on the nearside of the ridge axis. For cases with no longterm interaction (Figures $4 \mathrm{e}$ and $4 \mathrm{f}$ ), a small fraction of plume material is diverted toward the ridge axis, but fails to get as far as the ridge extraction box.

[22] The degree to which the plume interacts with the ridge axis can be quantified more precisely by considering the dimensionless plume flux to the ridge axis $\left(Q^{*}\right)$. In this case, $Q^{*}$ ranges from values of zero for non-interaction cases (i.e., $\left.P^{*}<0.5\right)$ to values slightly greater than 0.5 for $P^{*}>1.9$ (Figure 5). This behavior is similar to that observed in previous studies of chemically buoyant plumes [Kincaid et al., 1996], and is consistent with studies in which the maximum distance of plume-ridge interaction, $x_{\max }$, varies as $x_{\max } \sim\left(Q^{*} / U_{\mathrm{o}}\right)^{(1 / 2)}$ [Ito et al., 1997]. A series of control experiments which disregarded melting and latent heating effects resulted in a similar pattern of behavior, though generally offset to slightly higher values of $Q^{*}$ relative to the cases with melting (Figure 5). This difference is due to the fact that the loss of thermal energy to latent heating during melting reduces the temperature of the plume material. This both reduces its buoyancy and increases its viscosity, resulting in less vigorous plume flow. For cases both with and without melting, $Q^{*}$ appears to approach an asymptotic limit slightly greater than 0.5 for values of $P^{*}>1.9$.

\subsection{Fe Depletion Buoyancy}

[23] A series of experiments were conducted to consider the effect of increased buoyancy due to depletion of $\mathrm{Fe}$ during melting on plume-ridge interaction. Fe depletion buoyancy had little effect on flow morphology, with temperature and composition fields closely resembling those of experiments with melting in the absence of Fe depletion effects (e.g., Figure 4). Models with Fe depletion buoyancy did exhibit slightly enhanced values of $Q^{*}$ relative to cases without $\mathrm{Fe}$ depletion effects, with values of $Q^{*}$ approaching 0.56 for large values 

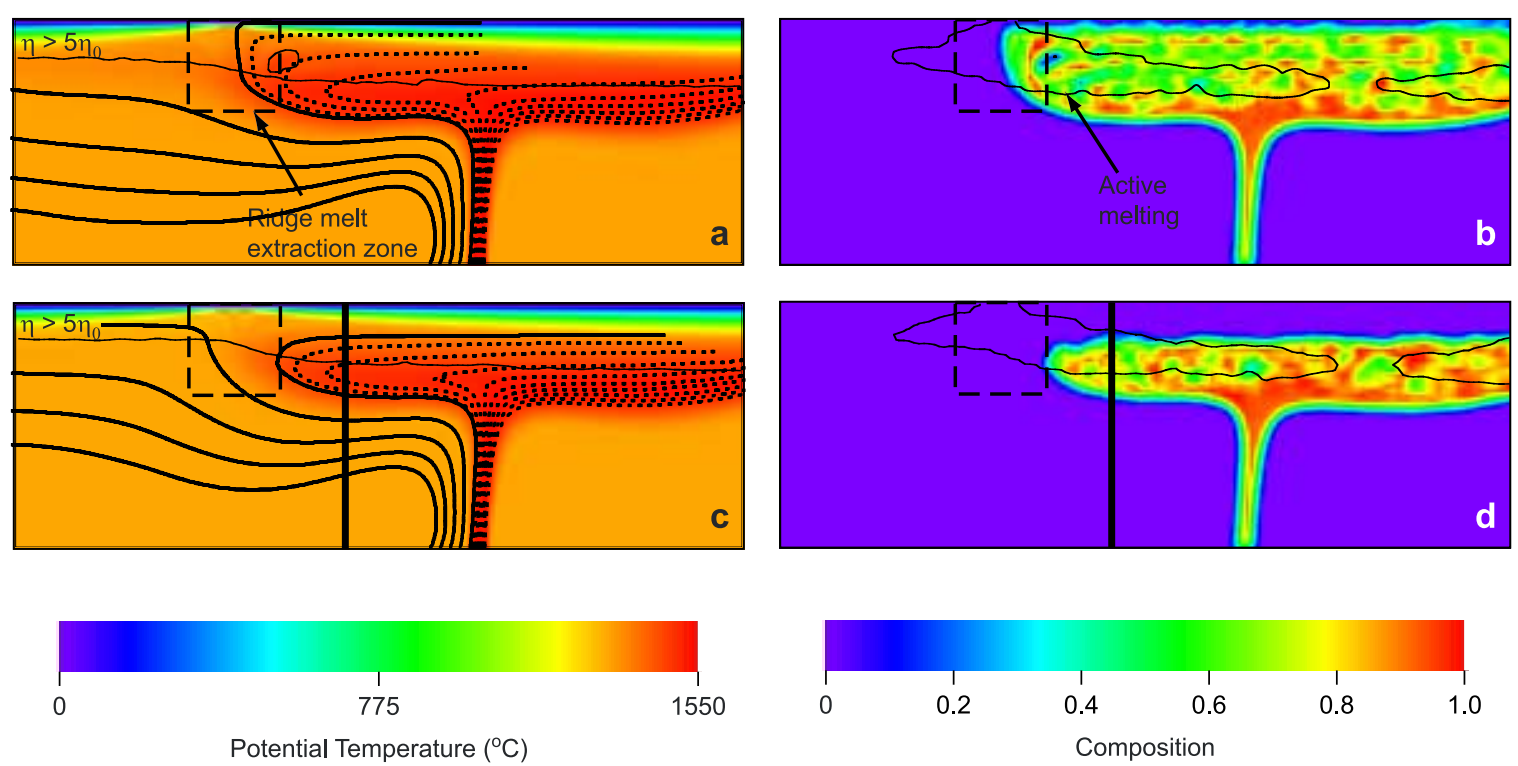

Figure 6. Temperature (left) and composition (right) fields for two model runs in which viscosity increases associated with dehydration during melting accounted for: $\mathrm{a}, \mathrm{b}) P^{*}=0.9\left(\mathrm{E}=30, \eta / \eta_{0}=0.1, \mathrm{Pe}=600\right)$;, $\left.\mathrm{d}\right) P^{*}=0.6$ $\left(\mathrm{E}=30, \eta / \eta_{0}=0.1, \mathrm{Pe}=900\right)$. The path lines of selected mantle (solid) and plume (dotted) particles are superimposed on the temperature field. The base of the rheological lithosphere, defined by the $\eta=5 \eta_{\mathrm{o}}$ isoviscous contour is overlain in a and c. Regions of active melt generation are outlined in $b$ and $d$. The bold vertical line in $c$ and $d$ marks the location of the vertical profile shown in Figure 8. Composition is obtained by normalizing the number of plume particles in a given computational cell by the maximum initial number of particles per cell.

of $P^{*}$ (Figure 5). This reflects the fact that the increased buoyancy results in slightly more vigorous plume flow.

\subsection{Dehydration}

[24] A series of experiments were conducted to investigate the effect of viscosity increases due to dehydration during melting on plume-ridge interaction. These experiments resulted in markedly different flow morphologies than cases without dehydration effects, demonstrated most dramatically in the substantially deeper position of the $\eta=$ $5 \eta_{o}$ viscosity contour above the plume conduit (Figure 6). This reflects the creation of two highviscosity layers due to dehydration during melting. The first layer is created by decompression melting of ambient mantle material at the ridge, which generates a uniform layer of high-viscosity material at depths above the solidus depth for ambient mantle [Hirth and Kohlstedt, 1996; Phipps Morgan, 1997; Ito et al., 1999]. The second layer is created by decompression melting of the upwelling plume material, which generates a layer with similarly high viscosities. This layer is found at greater depths than the first layer, because of the relatively higher temperature of the plume material. Unlike the first layer, it is spatially limited, occurring only in regions with plume material. The presence of this viscous plug of depleted plume material causes plume particle trajectories to be deflected horizontally at substantially greater depths than would otherwise be expected. In fact, much of the plume material travels horizontally to the ridge axis at subsolidus depths, and therefore experiences no melting before reaching the ridge. This behavior might be modified somewhat if melting between the wet and dry solidus were considered explicitly. Plume material that does experience melting en route to the ridge is rapidly incorporated into the viscous plug as its viscosity increases and therefore fails to reach the ridge. The plug itself is thus composed of thermally buoyant plume material that has experienced small degrees of melting and only gradually loses heat by conduction to the cold lithosphere above.

[25] For the strongest interaction cases (Figures 6a and $6 \mathrm{~b}$ ), a smaller fraction of plume material reaches the ridge axis than in comparable cases 
without dehydration effects (e.g., 1 plume particle trajectory in Figure 6a as opposed to 3 in Figure 4a), and plume particle trajectories in the ridge extraction region are much steeper. These particles therefore experience much greater melting due to decompression at the ridge than in cases without dehydration effects. Plume material is only incorporated into the lithosphere on the nearside of the ridge axis. Thus the strongest interaction cases with dehydration more closely resemble cases of moderate interaction, rather than strong interaction, without dehydration. Cases with no interaction between plume and ridge (Figures $6 \mathrm{c}$ and $6 \mathrm{~d}$ ) also show a substantial viscous plug and the consequent horizontal deflection of plume particles at subsolidus depths. These conditions are observed at slightly greater values of $P^{*}$ than in cases without dehydration.

[26] Models with dehydration effects exhibited significantly smaller values of $Q^{*}$ relative to cases without dehydration effects (Figure 5). Slightly higher values of $P^{*}$ are necessary to achieve any flux of plume material to the ridge axis under these circumstances, indicating that stronger plume flow is necessary to achieve plume-ridge communication when dehydration effects are considered. In addition, for very strong plume flow (i.e., $P^{*}>1.9$ ), $Q^{*}$ approaches a value of approximately 0.35 for cases with dehydration, as opposed to values of $Q^{*}>0.5$ for cases without dehydration effects. This represents a reduction in the flow of plume material to the ridge of approximately $30 \%$. This difference is due to the fact that a substantial portion of the plume material moving toward the ridge axis is incorporated into the viscous plug as it begins to melt, prior to reaching the ridge axis.

\subsection{Rheological Boundary Layer Slope}

[27] The effect of RBL slope on plume-ridge interaction was investigated for cases both without and with dehydration related viscosity effects. A series of experiments was conducted in which the dimensionless activation energy, E, was varied between $0 \leqslant E \leqslant 30$ while plate speed and plume viscosity contrast were held constant at $\mathrm{Pe}=300$ (corresponding to $U_{o}=2.4 \mathrm{~cm} \mathrm{yr}^{-1}$ )
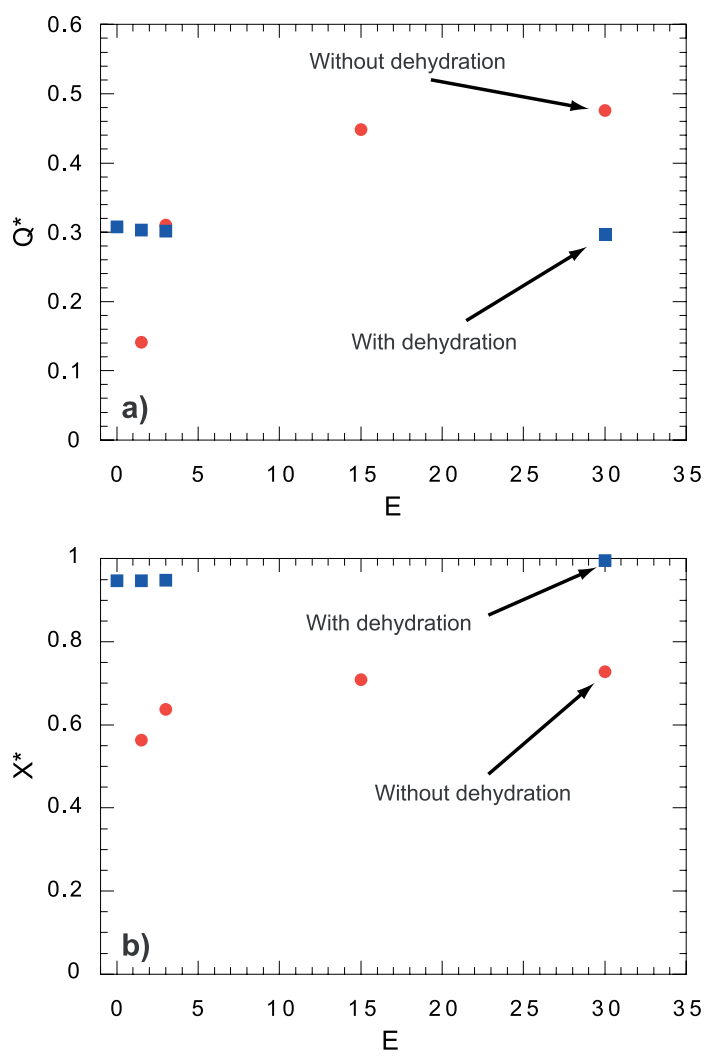

Figure 7. Plots of a) fractional plume flow to the ridge axis $\left(Q^{*}\right)$ and b) axial plume concentration $\left(X^{*}\right)$ as a function of dimensionless activation energy (E) for cases with melting and latent heating (red circle) and melting, latent heating and dehydration (blue square). The value of E controls the slope of the RBL corresponding to the thermal lithosphere, with $\mathrm{E}=30$ leading to an $\mathrm{RBL}$ slope of $9^{\circ}$ while $\mathrm{E}=0$ leads to an RBL slope of $0^{\circ}$ (i.e., purely horizontal). While cases without dehydration show increasing plume flow to the ridge axis with increasing RBL slope, particularly for small slopes, cases with dehydration are independent of RBL slope. This is because dehydration produces a horizontal rheological boundary at depth within the mantle.

and $\eta / \Delta \eta_{o}=0.1$ respectively. As $E$ increases, the depth at which the isoviscous contour corresponding to the base of the RBL is encountered increases for a given temperature profile (Figure $3 b$ ). Hence, as E increases, the thickness of the mechanical lithosphere at a given point increases, and therefore so does the slope of the base of the lithosphere. A value of $\mathrm{E}=3$ yields an $\mathrm{RBL}$ with a slope of approximately $4^{\circ}$ to the horizontal above the plume conduit while a value of $\mathrm{E}=30$ (the default for this study) gives a slope of approximately $9^{\circ}$. A value of $\mathrm{E}=0$ leads to the absence of a RBL. 
[28] In experiments without dehydration effects, the dimensionless flux of plume material to the ridge axis, $Q^{*}$ (Figure 7a), increases markedly with increasing values of $E$ (and hence steeper slopes). Likewise, the concentration of plume material at the ridge axis, $X^{*}$, increases with increasing RBL slope (Figure $7 \mathrm{~b}$ ). Both $Q^{*}$ and $X^{*}$ appear to be approaching asymptotic values for values of $E$ greater than 15. This sensitivity to RBL slope is in agreement with the results of previous studies of chemically buoyant plumes, which demonstrated a strong relationship between RBL slope and plume flow to the ridge axis [Kincaid et al., 1996].

[29] Interestingly, in experiments that consider dehydration effects, plume flow to the ridge axis is found to be largely insensitive to variations in activation energy (Figure 7). This is likely a result of the creation of a nearly horizontal RBL by dehydration of the upwelling plume material (Figure 6).

\section{Discussion}

\subsection{Geophysical Implications}

[30] Viscosity increases due to dehydration during melting can profoundly effect the spatial distribution of the thermal and chemical anomalies associated with the plume within the mantle itself. This can be demonstrated by comparing variations in properties along a vertical profile through the mantle for experiments with and without dehydration effects. Profiles for a set of experiments with $P^{*}=0.6(\mathrm{Pe}=900)$ are shown in Figure 8. Profiles are located between the plume and the ridge, $200 \mathrm{~km}$ from the ridge axis, as shown in Figures 4 and 6 . Reference profiles are taken at an equivalent distance on the opposite side of the ridge axis, where there is no plume influence, for each of these cases.

[31] The temperature anomaly associated with the plume can be obtained by subtracting the temperature along the reference profile from that of the particular profile of interest (Figure 8a). Cases with dehydration effects show a significantly larger thermal anomaly at much greater depth than cases without dehydration effects. The difference in the depth of the anomalies reflects the fact that plume material is deflected horizontally at greater depths in experiments with dehydration effects. The difference in the magnitude of the anomalies is due to the plume material having undergone less decompression melting in the dehydration case, and therefore having lost less thermal energy to latent heating.

[32] Variations in the degree to which the mantle has been depleted by melting related to the plume can similarly be obtained by subtracting values of $D$ along the reference profile from those along the profile of interest (Figure 8b). Experiments with dehydration effects exhibit smaller overall degrees of plume related melting than experiments without dehydration effects. In addition, this depletion is limited to greater depths relative to cases without dehydration. This reflects the fact that plume material rises to greater depths off-axis in cases without dehydration, thereby experiencing greater degrees of melting due to decompression.

[33] The thermal and compositional (i.e., depletion) anomalies associated with the plume result in a density anomaly, as encapsulated in the momentum equation (2). The differences in temperature and depletion between experiments with and without dehydration therefore lead to differences in density. Plots of the percentage change in density relative to the reference profile $(\delta \rho)$ are shown for experiments without (Figure 8c) and with (Figure 8d) dehydration effects, along with the separate contributions of thermal and compositional anomalies to the total density anomaly. Experiments with dehydration lead to deeper density anomalies off-axis, and smaller density anomalies at shallow depths (e.g., $<75 \mathrm{~km}$ ) (Figure 8e).

[34] Seismic waves are sensitive to both the temperature and composition of the material through which they propagate. The differences in thermal and compositional structure off-axis when dehydration effects are considered present the possibility of discriminating between the two models through seismic studies. This is particularly intriguing when considering the 3-dimensional extension of the viscous plug seen in experiments with dehydration effects (Figure 10). This plug will have a 

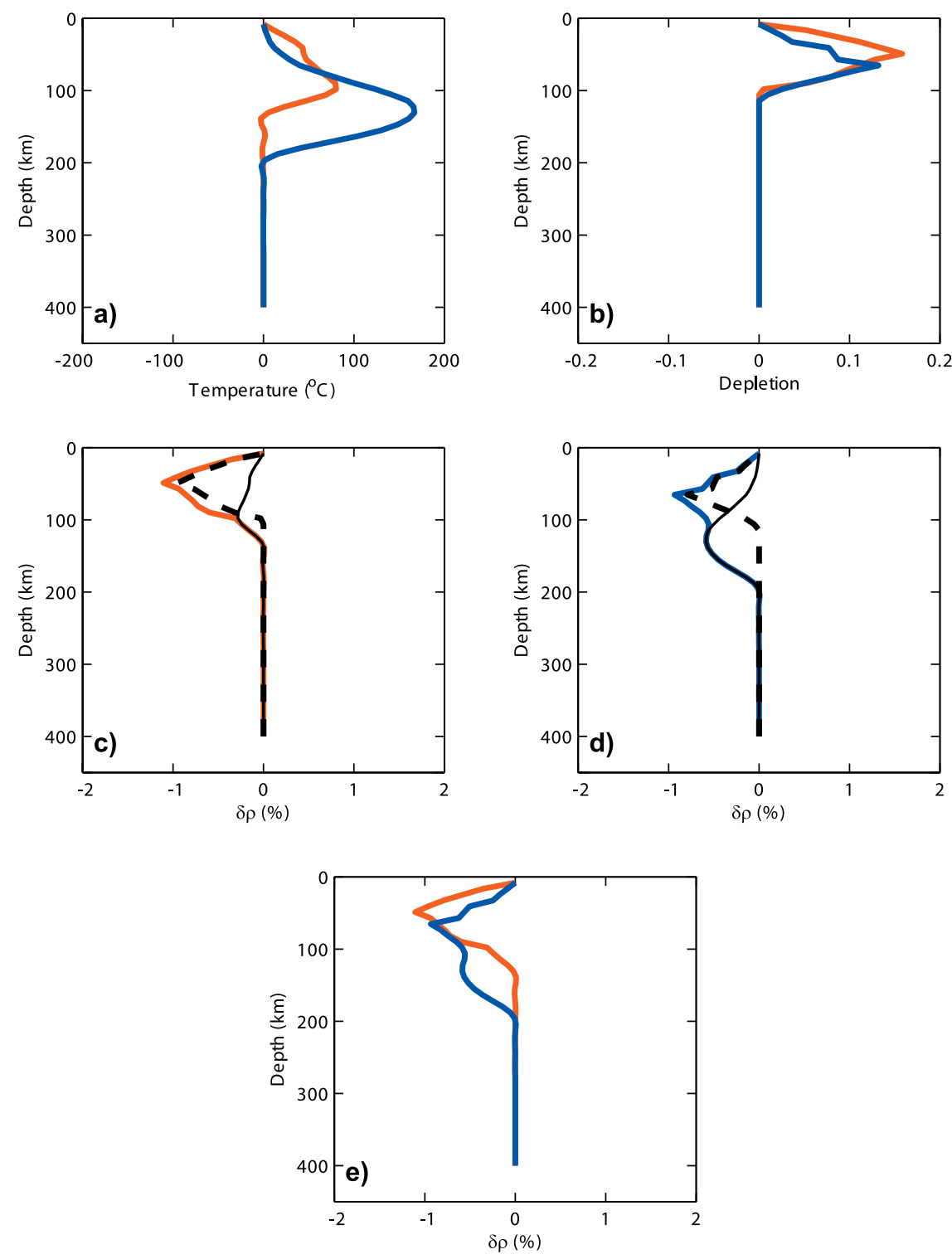

Figure 8. Profiles for experiments with $P^{*}=0.6(\mathrm{Pe}=900)$ both with (blue) and without (red) dehydration. a) Dimensional temperature difference relative to reference profile. b) Difference in depletion $(D)$ relative to reference profile. c) Ratio of density to reference density for case without dehydration (solid red line). Solid black line shows density difference due exclusively to thermal effects while the dashed black line shows density differences due to compositional differences related to melting. d) Ratio of density to reference density for case with dehydration (solid blue line). Solid black line shows density difference due exclusively to thermal effects while the dashed black line shows density differences due to compositional differences related to melting. e) Ratio of density to reference density for case without (red) and with (blue) dehydration.

finite width in the direction perpendicular to plate motion, related directly to the plume flux and inversely to plate velocity. At the same time, its length in the direction of plate motion will be in accordance with the age of the plume and the plate velocity. The boundaries of the plug should be sharp, as is the case at the ridge axis. These relatively large regions of anomalously warm, viscous, low-density material at the base of the lithosphere might prove to be detectable by seismic means.

\subsection{Geochemical Implications}

[35] Variations in trace element concentrations and isotope ratios along mid-ocean ridges are of pri- 
mary importance in identifying and quantifying plume-ridge interaction observationally. Plume material is believed to be, in general, more enriched in highly incompatible elements such as the light rare earth elements (LREE) than is the depleted MORB mantle (DMM), which is representative of the upper mantle as sampled at ridge axes. Regions of ridge axis exhibiting anomalously high concentrations of highly incompatible elements, or large ratios of highly incompatible elements to moderately incompatible elements (e.g., La/Sm) may thus be considered potential examples of plume-ridge interaction. Examples of off-axis plume-ridge systems that have been identified geochemically include the Easter-Salas y Gomez seamount chain [Kingsley and Schilling, 1998], Discovery (MidAtlantic Ridge) [Douglass et al., 1995, 1999], and the Galapagos Archipelago (Galapagos spreading center) [Schilling et al., 1982; Harpp and White, 2001]. To better interpret these geochemical anomalies in terms of the underlying dynamics, it is necessary to understand the geochemical consequences of the various plume-ridge flow regimes. This can be done in a simple way by considering the degree to which plume material has experienced melting and melt extraction prior to reaching the ridge extraction zone, as given by $D^{*}$, for a range of plume-ridge interaction scenarios.

[36] A plot of $D^{*}$ as a function of $P^{*}$ for the experiments presented here reveals several interesting results (Figure 9). First of all, for cases without dehydration effects, the degree of melting experienced by plume material before reaching the ridge axis increases as plate speed increases and plume strength decreases (i.e., $P^{*}$ decreases). At the limit of communication, plume material experiences an average depletion of $18 \%$ prior to reaching the ridge axis. This material would therefore be severely depleted of incompatible elements and unable to generate the signature incompatible trace element enrichment associated with plumes. At the other extreme of strong communication (i.e., strong plume flow and weak plate flow associated with large values of $P^{*}$ ) plume material only experiences an average depletion of approximately $6 \%$ off-axis. Thus the plume material would retain much more of its incompatible element signature. Values of $D^{*}$ for

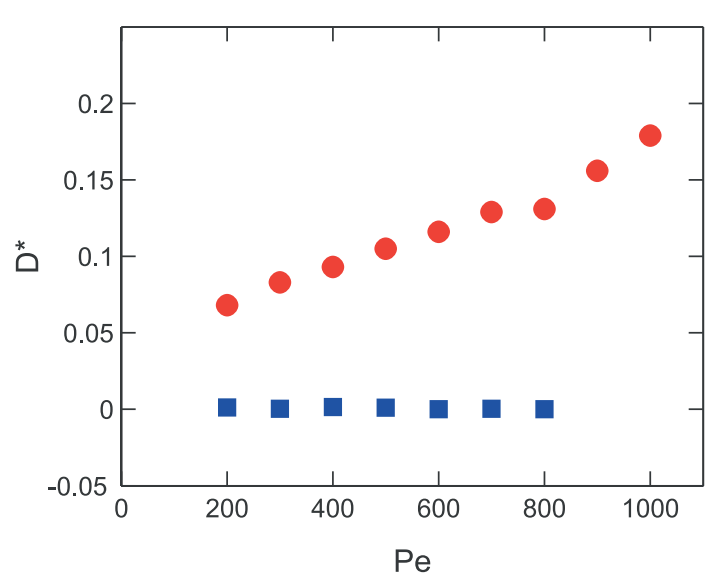

Figure 9. Average melt depletion experienced by plume material prior to entering the ridge melt extraction zone $\left(D^{*}\right)$ as a function of the plate Peclet number $(\mathrm{Pe})$ for cases with melting and latent heat effects (red cirlce) and melting, latent heating and dehydration (blue square). In cases without dehydration, plume material experiences considerable off-axis melting due to the vertical component of plume velocity at subsolidus depths. In cases with dehydration, plume material experiences little or no melting off-axis. This is due to the presence of a thick, viscous plug over the plume conduit that deflects plume flow horizontally, delaying decompression until the plume material is very close to the ridge axis.

cases without dehydration effects approach a value of approximately $6 \%$ as the degree of plume-ridge communication increases (i.e., $P^{*}$ increases). This variation in $D^{*}$ reflects the degree to which plume material experiences decompression melting off axis. As plate speed increases (and thus $P^{*}$ decreases), the lithosphere above the plume conduit becomes younger, and therefore thinner. Thinner lithosphere means that plume particles can ascend to shallower depths before being deflected to travel horizontally to the ridge axis. This additional vertical motion results in additional decompression and therefore higher degrees of melting off-axis. However, observations indicate that the degree to which plumes melt is relatively insensitive to the age of the overlying lithosphere [Phipps Morgan, 1997].

[37] When dehydration effects are considered, a significantly different picture emerges. In these scenarios, $D^{*}$ is independent of the degree of plume-ridge communication, and is essentially equal to zero at all times. Thus plume material 
a)

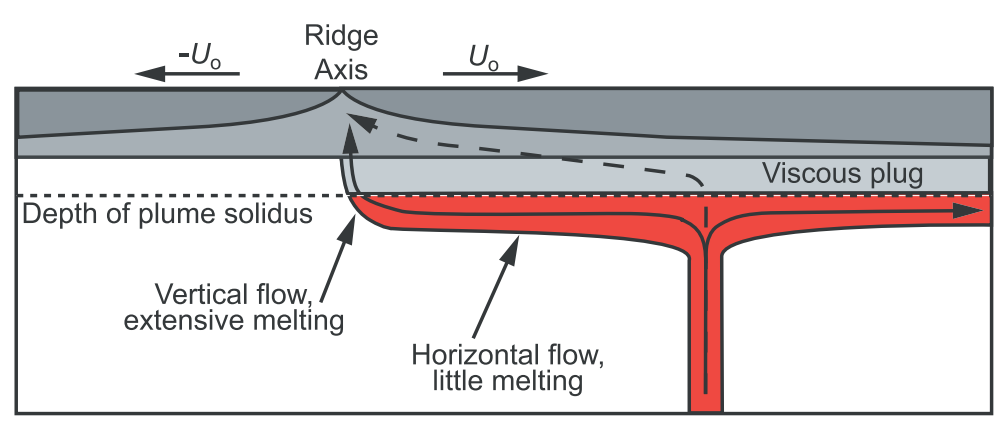

b)

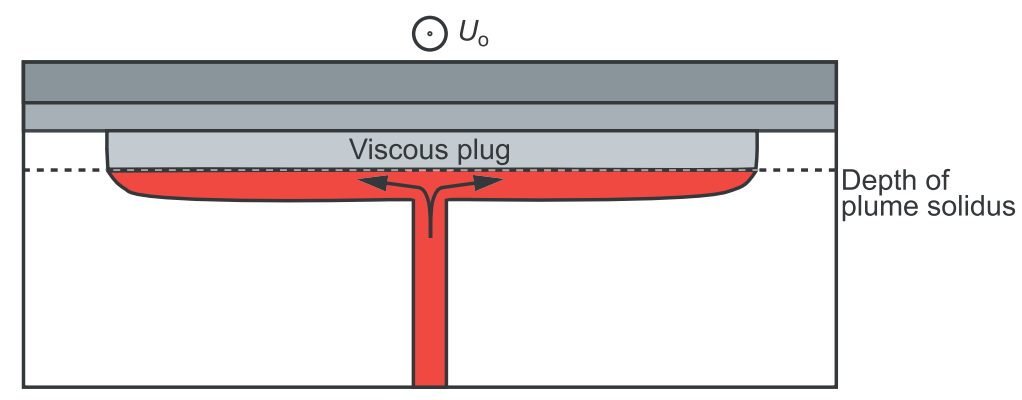

Figure 10. Cartoon illustration of off-axis plume flow with dehydration related viscosity increases. a) Cross sectional view through the plume, perpendicular to the ridge axis. The schematic path of plume flow to the ridge in the absence of dehydration effects is shown as a dashed line for comparison. The dotted horizontal line is the depth at which plume material begins to melt. The region of high-viscosity material comprising the viscous plug created by melting and dehydration of plume material is shown as light gray. The high-viscosity layer created by melting and dehydration of ambient mantle and/or plume mantle is shown as medium gray. b) Cross sectional view through the plume, parallel to the ridge axis. Plate velocity is directed out of the page with magnitude $U_{0}$, as indicated.

reaching the ridge axis is essentially pristine, having undergone little or no melting off-axis. This material would then impart a strong plume signature on the geochemistry of melts produced at the ridge axis. This is the result of the nearly horizontal RBL created by the dehydration of upwelling plume material. Once this viscous plug is established, subsequent plume material is deflected nearly horizontally along its base at subsolidus depths. Material melting even slightly as it moves toward the ridge axis is readily accreted to this plug as its viscosity increases, maintaining the size and shape of the plug as it is moved away from the ridge axis by the motion of the overlying plate. Thus the only plume material to reach the ridge axis is unmelted.

\section{Conclusions}

[38] We have presented results from a series of 2-D numerical experiments in which a thermally buoyant plume interacts with a nearby ridge axis. We find that dehydration related increases in the viscosity of the residual mantle during melting profoundly alter the morphology of flow between plume and ridge axis. In the absence of dehydration an upwelling plume will experience substantial melting off-axis due to decompression as it travels subhorizontally along the base of the lithosphere en route to the ridge axis. This off-axis melting depletes the plume material of highly incompatible elements before it reaches the ridge. With dehydration, however, a viscous plug forms at the base of the lithosphere as the ascending plume begins to melt (Figure 10). This plug creates a horizontal boundary that deflects plume material toward the ridge axis at subsolidus depths. Since the plume material experiences little or no decompression melting off-axis it will not be depleted of incompatible elements prior to reaching the ridge. This implies a significantly different magma source chemistry at the ridge than would be expected without dehydration. 
[39] While the experiments conducted here are two-dimensional, they suggest some interesting aspects of three-dimensional flow in plume-ridge systems. In particular, the viscous plug generated by dehydration of the upwelling plume should have a finite width in the direction perpendicular to plate motion (Figure 10b), while extending in the direction of plate motion in accordance with the age of the plume and the plate velocity. The boundaries of the plug should be sharp, as is the boundary at the ridge axis. These relatively large regions of anomalously warm, viscous, low-density material at the base of the lithosphere might prove to be detectable by seismic or other geophysical means.

\section{Acknowledgments}

[40] This work was supported by National Science Foundation grant OCE-9618315. We are grateful to Bill White, Garrett Ito and Greg Hirth for their careful and thoughtful reviews and to Jean-Guy Schilling for his very constructive comments.

\section{References}

Braun, M. G., G. Hirth, and E. M. Parmentier, The effects of deep damp melting on mantle flow and melt generation beneath mid-ocean ridges, Earth Planet. Sci. Lett., 176, 339-356, 2000.

Cordery, M., and J. Phipps Morgan, Convection and melting at mid-ocean ridges, J. Geophys. Res., 98, 19,477-19,503, 1993.

Douglass, J., J.-G. Shilling, R. Kingsley, and C. Small, Influence of the Discovery and Shona mantle plumes on the southern Mid-Atlantic Ridge: Rare earth evidence, Geophys. Res. Lett., 22, 2893-2896, 1995.

Douglass, J., J.-G. Shilling, and D. Fontignie, Plume-ridge interactions of the Discovery and Shona mantle plumes with the southern Mid-Atlantic Ridge $\left(40^{\circ}-50^{\circ} \mathrm{S}\right)$, J. Geophys. Res., 104, 2941-2962, 1999.

Feighner, M. A., and M. A. Richards, The fluid dynamics of plume-ridge and plume-plate interactions: An experimental investigation, Earth Planet. Sci. Lett., 129, 171-182, 1995.

Griffiths, R. W., and I. H. Campbell, Interaction of mantle plume heads with the Earth's surface and onset of small-scale convection, J. Geophys. Res., 96, 18,295-18,310, 1991.

Hall, C. E., and E. M. Parmentier, Spontaneous melt localization in a deforming solid with viscosity variations due to water weakening, Geophys. Res. Lett., 27, 9-12, 2000.

Harpp, K. S., and W. M. White, Tracing a mantle plume: Isotopic and trace element variations of Galápagos seamounts, Geochem. Geophys. Geosyst., 2, Paper number 2000GC000137, 2001.
Hart, S. R., J.-G. Schilling, and J. L. Powell, Basalts from Iceland and along the Reykjanes Ridge: Sr isotope geochemistry, Nature, 246, 104-107, 1973.

Hirth, G., and D. L. Kohlstedt, Water in the oceanic upper mantle: Implications for rheology, melt extraction and the evolution of the lithosphere, Earth Planet. Sci. Lett., 144, 93-108, 1996.

Hughes, T. J. R., The Finite Element Method, 631 pp., PrenticeHall, Old Tappan, N. J., 1987.

Ito, G., Reykjanes 'V'-shaped ridges originating from a pulsing and dehydrating mantle plume, Nature, 411, 681-684, 2001.

Ito, G., and J. Lin, Oceanic spreading center-hotspot interaction: Constraints from along-isochron bathymetric and gravity anomalies, Geology, 23, 657-660, 1995.

Ito, G., J. Lin, and C. W. Gable, Dynamics of mantle flow and melting at a ridge-centered hotspot: Iceland and the MidAtlantic Ridge, Earth Planet. Sci. Lett., 144, 53-74, 1996.

Ito, G., J. Lin, and C. W. Gable, Interaction of mantle plumes and migrating mid-ocean ridges: Implications for the Galápagos plume-ridge system, J. Geophys. Res., 102, 15,40315,417, 1997.

Ito, G., Y. Shen, G. Hirth, and C. J. Wolfe, Mantle flow, melting, and dehydration of the Iceland mantle plume, Earth Planet. Sci. Lett., 165, 81-96, 1999.

Jha, K., E. M. Parmentier, and J. Phipps Morgan, The role of mantle-depletion and melt-retention buoyancy in spreadingcenter segmentation, Earth Planet. Sci. Lett., 125, 221-234, 1994.

Kincaid, C., and P. S. Hall, Role of back arc spreading in circulation and melting at subduction zones, J. Geophys. Res., 108(B5), 2240, doi:10.1029/2001JB001174, 2003.

Kincaid, C., and S. Sacks, The thermal and dynamical evolution of the upper mantle in subduction zones, J. Geophys. Res., 102, 12,295-12,315, 1997.

Kincaid, C., G. Ito, and C. Gable, Laboratory investigation of the interaction of off-axis mantle plumes and spreading centers, Nature, 376, 758-761, 1995.

Kincaid, C., J.-G. Schilling, and C. Gable, The dynamics of off-axis plume-ridge interaction in the uppermost mantle, Earth Planet. Sci. Lett., 137, 29-43, 1996.

Kingsley, R. H., and J.-G. Schilling, Plume-ridge interaction in the Easter-Salas y Gomez seamount chain-Easter Microplate system: $\mathrm{Pb}$ isotope evidence, J. Geophys. Res., 103, 24,15924,177, 1998.

Langmuir, C. H., E. M. Klein, and T. Plank, Petrological systematics of mid-ocean ridge basalts: Constraints on melt generation beneath mid-ocean ridges, in Mantle Flow and Melt Generation at Mid-Ocean Ridges, Geophys. Monogr. Ser., vol. 71, edited by J. Phipps Morgan, D. K. Blackman, and J. M. Sinton, pp. 183-280, AGU, Washington, D. C., 1992.

Leitch, A. M., G. F. Davies, and M. Wells, A plume head melting under a rifting margin, Earth Planet. Sci. Lett., 161, 161-177, 1998.

Manglik, A., and U. R. Christensen, Effect of mantle depletion buoyancy on plume flow and melting beneath a stationary plate, J. Geophys. Res., 102, 5019-5028, 1997. 
McKenzie, D., and M. J. Bickle, The volume and composition of melt generated by extension of the lithosphere, J. Petrol., 29, 625-679, 1988.

Morgan, W. J., Convection plumes in the lower mantle, Nature, 230, 42-43, 1971.

Morgan, W. J., Rodriquez, Darwin, Amsterdam...A second type of hotspot island, J. Geophys. Res., 83, 5355-5360, 1978.

Olson, P., G. Schubert, C. Anderson, and P. Goldman, Plume formation and lithosphere erosion: A comparison of laboratory and numerical experiments, J. Geophys. Res., 93, 15,065-15,084, 1988.

Phipps Morgan, J., The generation of a compositional lithosphere by mid-ocean ridge melting and its effect on subsequent off-axis hotspot upwelling and melting, Earth Planet. Sci. Lett., 146, 213-232, 1997.

Ribe, N. M., The dynamics of plume-ridge interaction: 2. Offridge plumes, J. Geophys. Res., 101, 16,195-16,204, 1996.

Ribe, N. M., and U. R. Christensen, The dynamical origin of Hawaiian volcanism, Earth Planet. Sci. Lett., 171, 517-531, 1999.

Ribe, N. M., U. R. Christensen, and J. Theißing, The dynamics of plume-ridge interaction, 1: Ridge-centered plumes, Earth Planet. Sci. Lett., 134, 155-168, 1995.

Schilling, J.-G., Iceland mantle plume: Geochemical evidence along Reykjanes Ridge, Nature, 242, 565-571, 1973.

Schilling, J.-G., Upper mantle heterogeneities and dynamics, Nature, 314, 62-67, 1985.

Schilling, J.-G., Fluxes and excess temperatures of mantle plumes inferred from their interaction with migrating midocean ridges, Nature, 352, 397-403, 1991.

Schilling, J.-G., R. H. Kingsley, and J. D. Devine, Galapagos hot spot-spreading center system: 1 . Spatial petrological and geochemical variations $\left(83^{\circ} \mathrm{W}-101^{\circ} \mathrm{W}\right)$, J. Geophys. Res., 87, 5593-5610, 1982.
Schilling, J.-G., M. Zajac, R. Evans, R. Johnston, W. White, J. D. Devine, and R. Kingsley, Petrologic and geochemical variations along the Mid-Atlantic Ridge from $29^{\circ} \mathrm{N}$ to $37^{\circ} \mathrm{N}$, Am. J. Sci., 283, 510-586, 1983.

Schilling, J.-G., R. Kingsley, D. Fontignie, R. Poreda, and S. Xue, Dispersion of the Jan Mayen and Iceland mantle plumes in the Arctic: A He-Pb-Nd-Sr isotope tracer study of basalts from the Kolbeinsey, Mohns, and Knipovich Ridges, J. Geophys. Res., 104, 10,543-10,569, 1999.

Small, C., Observations of ridge-hotspot interactions in the Southern Ocean, J. Geophys. Res., 100, 17,931-17,946, 1995.

Sparks, D. W., and E. M. Parmentier, The structure of threedimensional convection beneath oceanic spreading centers, Geophys. J. Int., 112, 81-91, 1993.

$\mathrm{Su}$, W., and W. R. Buck, Buoyancy effects on mantle flow under mid-ocean ridges, J. Geophys. Res., 98, 12,19112,205, 1993.

Sun, S.-S., M. Tatsumoto, and J.-G. Schilling, Mantle plume mixing along the Reykjanes Ridge axis: Lead isotopic evidence, Science, 190, 143-147, 1975.

Travis, B., C. J. Anderson, J. Baumgardner, C. W. Gable, B. H. Hager, R. J. O'Connell, P. Olson, A. Raefsky, and G. Schubert, A benchmark comparison of numerical methods for infinite Prandtl number convection in a two-dimensional geometry, Geophys. Astrophys. Fluid Dyn., 55, 137-160, 1991.

Vogt, P. R., Asthenosphere motion recorded by the ocean floor south of Iceland, Earth Planet. Sci. Lett., 13, 153-160, 1971.

Wallace, P. J., Water and partial melting in mantle plumes: Inferences from the dissolved $\mathrm{H}_{2} \mathrm{O}$ concentrations of Hawaiian basaltic magmas, Geophys. Res. Lett., 25, 3639-3642, 1998.

Weinstein, S. A., and P. L. Olson, The proximity of hotspots to convergent and divergent plate boundaries, Geophys. Res. Lett., 16, 433-436, 1989. 